\title{
The Impact of Childhood Obesity on Skeletal Health and Development
}

\author{
Paul Dimitri* \\ Academic Unit of Child Health, The University of Sheffield, Sheffield, UK
}

Increased risk of fracture identified in obese children has led to a focus on the relationship between fat, bone, and the impact of obesity during skeletal development. Early studies have suggested that despite increased fracture risk, obese children have a higher bone mass. However, body size corrections applied to account for wide variations in size between children led to the finding that obese children have a lower total body and regional bone mass relative to their body size. Advances in skeletal imaging have shifted the focus from quantity of bone in obese children to evaluating the changes in bone microarchitecture that result in a change in bone quality and strength. The findings suggest that bone strength in the appendicular skeleton does not appropriately adapt to an increase in body size which results in a mismatch between bone strength and force from falls. Recent evidence points to differing influences of fat compartments on skeletal development-visceral fat may have a negative impact on bone which may be related to the associated adverse metabolic environment, while marrow adipose tissue may have an independent effect on trabecular bone development in obese children. The role of brown fat has received recent attention, demonstrating differences in the influence on bone mass between white and brown adipose tissues. Obesity results in a shift in growth and pubertal hormones as well as influences bone development through the altered release of adipokines. The change in the hormonal milieu provides an important insight into the skeletal changes observed in childhood obesity.

Received January 14, 2019

Reviewed January 24, 2019

Accepted February 18, 2019

${ }^{*}$ Corresponding author Paul Dimitri

(i) https://orcid.org/0000-0001-7625-6713

Academic Unit of Child Health, The University of Sheffield, Sheffield Children's NHS Foundation Trust, Western Bank, Sheffield S10 2TH, UK Tel: +44-271-7118

Fax: +44-275-5364

E-mail: paul.dimitri@sch.nhs.uk

Key words: Bone, Child, Obesity, Fracture, Marrow, Hormone

\section{INTRODUCTION}

Childhood and adolescence marks a period of significant skeletal development and maturation. Cellular activity in the bone microenvironment favors net bone gain with the greatest increases in bone mass taking place during adolescence, a period of peak bone mass accrual. ${ }^{1}$ Whilst up to $80 \%$ of peak bone mass is genetically determined, the remaining $20 \%$ is modulated by environmental factors ${ }^{2}$ which have the potential to result in a deviation away from the normal trajectory of bone mass accrual, and if deleterious, may result in low bone mineral density (BMD) and an increased risk of fracture in childhood (Fig. 1). Furthermore, it is now well-accepted that factors that impact bone mass in childhood are important de- terminants of osteoporotic risk later in life ${ }^{3}$, thus highlighting the importance of maximizing bone mass accrual during skeletal development. ${ }^{4}$ Evidence over the last two decades demonstrating that obese children are overrepresented in fracture groups ${ }^{5-9}$ has raised concerns that the global rise in childhood obesity could have a significant impact on bone heath in the short- and long-term. This was considered particularly important given that adolescence is a time when there is a considerable rise in the incidence of fracture ${ }^{10}$ due to changes in bone microarchitecture. ${ }^{11-13}$ Fractures occur in nearly one in three children who are otherwise healthy ${ }^{11}$, and children who suffer a fracture are two to three times more likely to sustain a repeat fracture compared to age-matched peers with no fracture history. ${ }^{14}$ Therefore, a significant body of work has emerged in

Copyright (C) 2019 Korean Society for the Study of Obesity

(a) This is an Open Access article distributed under the terms of the Creative Commons Attribution Non-Commercial License (http://creativecommons.org/licenses/by-nc/4.o/) which permits unrestricted non-commercial use, distribution, and reproduction in any medium, provided the original work is properly cited. 


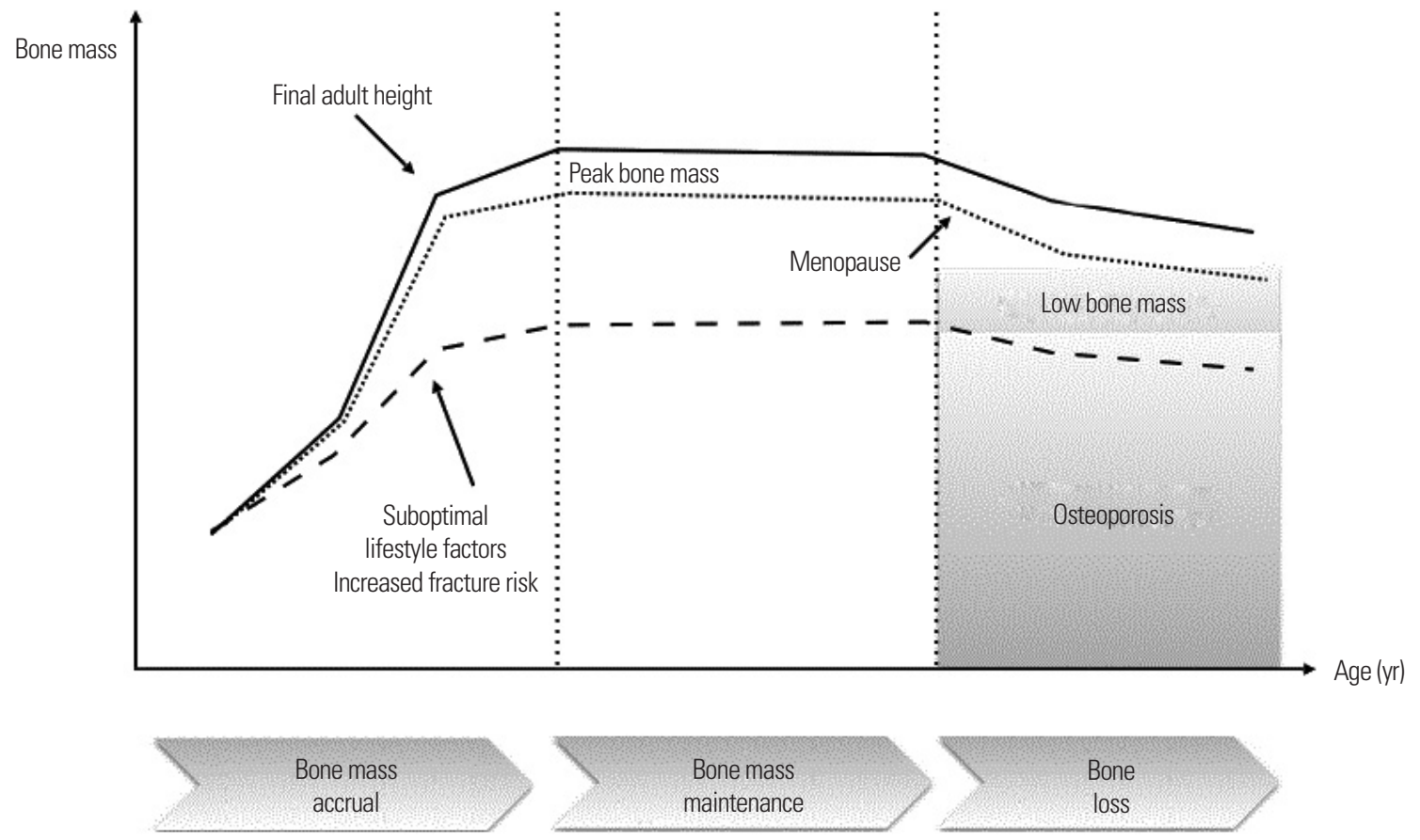

Figure 1. Bone mass acquisition during childhood. Up to $25 \%$ of peak bone mass accrual occurs during adolescence with subsequent bone loss in later life. Suboptimal lifestyle factors (which may include childhood obesity in adolescence) have an impact on bone mass accrual and peak bone mass increasing fracture risk and osteoporosis later in life.

an attempt to understand the impact of childhood obesity on skeletal health in children. On a pragmatic level, some have suggested that the increase in fracture risk simply results from the increased propensity to falls seen in obese children due to changes in postural stability and gait. ${ }^{15-17}$ However, this also raises the question as to whether there has been a suboptimal response of skeletal adaption to body size resulting in a mismatch between body and bone size thus increasing fracture risk. The improved resolution of skeletal imaging modalities has led to a shift towards considering the relevant biomechanical differences in the skeleton observed in obese children and elucidating differences in bone microarchitecture. Given that bone and fat are metabolically active tissues, changes in the hormonal milieu during growth and development and alternations in the bone marrow microenvironment have provided some insight into the mechanisms that may result in changes in the skeletal structure in childhood obesity. Specific skeletal sites (e.g., weightbearing versus non-weight-bearing) as well as skeletal compartments (e.g., cortical versus trabecular) may also be differentially affected by obesity. Moreover, as with other metabolic risk factors, the deleterious effect of fat on bone may be confined to visceral fat deposits. ${ }^{18,19}$

\section{THE IMPACT OF CHILDHOOD OBESITY ON BONE MASS}

Fractures during growth can be associated with skeletal fragility. ${ }^{20,21}$ A recent systematic review demonstrated that obese children are $25 \%$ more likely to experience an extremity fracture suggesting that appropriate skeletal adaptation to increasing body mass does not take place. ${ }^{22}$ A recent study reviewing the medical records of 913,178 children aged 2-19 years reported that moderately obese and extremely obese children had an increased odds ratio (OR) of lower limb fractures including those of the foot (OR, 1.23 and 1.42, respectively, with $95 \%$ confidence interval [CI], 1.12-1.35 and 1.26-1.61, respectively) along with the leg (OR, 1.51; 95\% CI, $1.33-1.72$ ) with children aged 6-11 at the greatest risk of lower extremity fractures. ${ }^{23}$ Evidence demonstrating that obese children are at an increased risk of fracture originally led to studies using dual energy x-ray absorptiometry (DXA) to determine whether obesity impacted the developing skeleton. However, using a scanning modality that utilized two-dimensional imaging to evaluate a three-dimensional structure created challenges with interpreting findings 
leading to conflicting studies, either demonstrating a positive or deleterious effect of fat mass on bone, with others suggesting that no relationship existed, citing lean mass rather than fat mass as the constituent of body composition that best predicted bone density. DXA measured areal bone density $\left(\mathrm{g} / \mathrm{cm}^{2}\right)$, overestimates true bone density $\left(\mathrm{g} / \mathrm{cm}^{3}\right)$ in taller children with larger bones, and underestimates true bone density in shorter children with smaller bones ${ }^{24}$ creating challenges in the measurement of bone density in obese children who are taller for their age and enter into puberty at an earlier age. A recent meta-analysis of the literature incorporating 27 studies and 5,958 children aged 2 to 18 years demonstrated that obese children have higher BMD and bone mineral content compared to children of normal weight. ${ }^{25}$ However, body size was not accounted for in this meta-analysis implying that bone density may have been inherently overestimated due to body size. In studies where bone mass is corrected for body size, several studies have demonstrated that bone mass is reduced in obese children, particularly in those that have a previous history of fracture ${ }^{26}$ though this finding appears to be inconsistent. ${ }^{27}$ To date, no agreement has been reached regarding the most reliable method to limit size-dependence for areal BMD.

The strong influence of genes on skeletal development means that bone mass "tracks" through childhood ${ }^{28}$ and low bone mass seen in early childhood persists into adulthood. ${ }^{29}$ Achieving optimal peak bone mass in childhood may result in the delayed onset of osteoporosis later in life and reduce fracture risk. ${ }^{3,28}$ During growth, absolute or relative gains in lean mass and fat mass appear to result in a positive or negative deviation from bone mass tracking, respectively, suggesting that body composition may be one of the key modifiable factors that determines bone mass accrual. ${ }^{30} \mathrm{Ex}$ cess fat mass may directly impact bone mass accrual or indirectly impact the positive effect of lean mass on bone during growth. $\mathrm{Cu}$ mulatively, however, cross-sectional studies suggest differential effects of obesity on bone in relation to age. Studies in young children have demonstrated a positive relationship between obesity and bone mass, which starts to attenuate later in childhood and then reverses during adolescence $e^{31-35}$ and could potentially persist into early adulthood. ${ }^{36}$ This changing relationship between obesity and bone during development may be altered in certain ethnic groups and in children who lead a more sedentary lifestyle. ${ }^{36,37}$
Therefore, differences seen across cross-sectional studies describing the impact of obesity on bone may be partially explained by the heterogenous age ranges and stage of pubertal development within and between studies. Furthermore, the contradictory findings seen across studies may be related to a "fat threshold" by which the deleterious effects of fat mass on bone during childhood may only be observed in relation to the accumulation of excess fat ${ }^{38}$ or following the evolution of an adverse metabolic profile. Recently, insulin resistance has been proposed as a key link between the negative relationship between fat mass and bone mass in obese children. ${ }^{39}$ Overweight prepubertal children with pre-diabetes and other cardiometabolic risk factors have a lower bone mass compared to those without risk factors, suggesting that the metabolic consequences of escalating adiposity may have an unfavorable impact on bone mass accrual and cortical development at a critical stage of development, resulting in an overall deficit in bone strength. ${ }^{40-42}$ However, other studies have shown that the overall influence of insulin resistance to bone mass in obese children may be relatively small, but may accumulate over time. ${ }^{43}$

\section{CHILDHOOD OBESITY AND BONE MICROARCHITECTURE}

The lack of agreement between studies using DXA to determine the relationship between childhood obesity and bone has prompted a move to determine the impact of excess fat mass on bone microarchitecture and biomechanics as the resolution and capability for bone imaging has improved over time. ${ }^{26}$ The introduction of peripheral quantitative computed tomography ( $\mathrm{pQCT}$ ) scanning and subsequent high-resolution pQCT (HRpQCT) has led to the ability to measure the volumetric parameters of the cortical and trabecular compartments in vivo. ${ }^{44}$ Studies using HRpQCT have the ability to determine microarchitectural changes in cortical and trabecular compartments due its ability to image bone to a resolution of $64 \mu \mathrm{m}$, providing a means for virtual in vivo "noninvasive bone biopsy" of the distal radius and tibia for the evaluation of cortical and trabecular volumetric components, trabecular connectivity, thickness and spacing, and cortical porosity (Fig. 2). Furthermore, the application of an engineering model known as micro-finite element analysis to HRpQCT images of the ultradistal tibia and radi- 

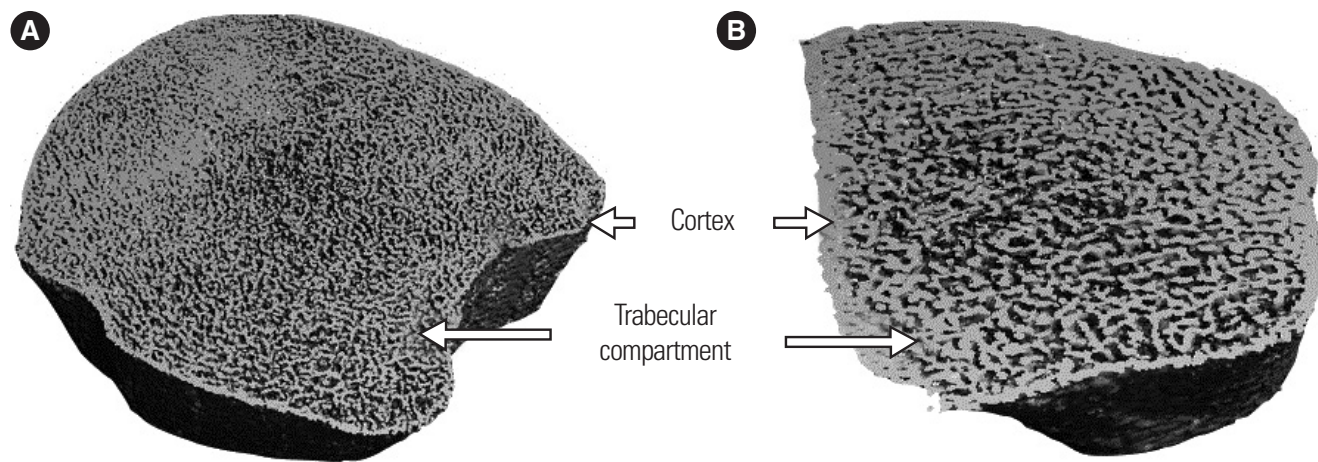

Figure 2. High-resolution peripheral quantitative computed tomography image of the distal $9 \mathrm{~mm}$ of left tibia $(\mathrm{A})$ and left radius $(\mathrm{B})$ in an adolescent healthy male showing trabecular and cortical compartments at high resolution.

us allows for the estimate of bone strength relative to load and stiffness. ${ }^{12,13,45}$ pQCT evaluates the trabecular and cortical bone compartments with an in-plane voxel dimension of $200 \mu \mathrm{m}$, calculating $\mathrm{BMD}$, and skeletal geometrical parameters including cortical crosssectional area (CSA), cortical thickness, periosteal and endosteal circumference, and biomechanical parameters including cross-sectional moment of inertia, a measure of bending, polar moment of inertia indicating bone strength in torsion, strength-strain index (SSI) at metaphysical sites, and bone strength index (BSI) at metaphyseal sites. BSI and SSI have been shown to predict up to $85 \%$ of the variance in bone failure properties in human cadaveric tissues suggesting that these are reasonable proxies of bone strength. ${ }^{46}$ The major advantage over HRpQCT is the ability of pQCT to define the CSA of muscle and fat which allows for a better understanding of the relationship between muscle and bone given that the current thinking is that these two compartments interact as a "muscle-bone unit." ${ }^{47}$ Despite the increase in spatial resolution in pQCT, there remains lack of clarity as to the relationship between obesity and bone in children and adolescents which may be in part related to the determination of the degree of adiposity. At a body mass index $(\mathrm{BMI})>85$ th percentile, children are reported to have increased bone strength at the tibia as compared to normal weight children (BMI $\leq 75$ th percentile), but bone strength is adapted to lean mass rather than fat mass. ${ }^{48}$ However, evidence suggests that the accumulation of site-specific deposits of fat may have an impact on the muscle-bone relationship resulting in a negative impact on cortical and trabecular compartments. ${ }^{49,50}$ Notably, an increase in the fat-muscle ratio at the radius is negatively correlated with bone strength and size which could explain the increased risk of radial fractures in obese children. ${ }^{49}$

To resist fracture from a fall, the developing skeleton should ideally adapt to body weight to prevent an increased risk of fracture. Despite the presence of a greater lean mass in obese children, skeletal adaptation does not appear to be sufficient to resist fracture. Studies using HRpQCT to compare bone microarchitecture between obese and lean children suggest that an appropriate increase in bone strength does not occur in obese children despite the increase in body weight ${ }^{51,52}$, or moreover, may be reduced in the tibia reflecting a negative impact of fat mass on bone strength in weight-bearing sites. ${ }^{51}$ Trabecular bone in obese children appears to undergo a reorganization by which trabeculae are thinner (which would confer a structural disadvantage), but trabecular numbers increase relative to a reduction in trabecular spacing which would confer a structural advantage. ${ }^{51,52}$ The timing and mechanism by which this reorganization occurs is not understood. Given the paucity of studies using HRpQCT, further investigations are required to delineate the longitudinal impact of obesity on skeletal microarchitecture and strength during skeletal development, whether the changes are sex specific, and to determine whether these changes persist into adulthood. Furthermore, the timing of skeletal changes and the "fat threshold" required that leads to these changes must be defined.

\section{CHILDHOOD OBESITY AND BONE MARROW FAT}

More recently, the adipogenic capacity of the marrow compartment in relation to bone mass in childhood has been examined. In elderly adults, bone loss with ageing is likely the consequence of 
preferential differentiation by mesenchymal cells into the adipocyte cell lineage such that osteoporosis may result from an increased number of adipocytes at the expense of osteoblasts. ${ }^{53,54}$ The finding that other pathologies with increased fracture risk including anorexia nervosa, Cushing disease, osteopenia, and those with poorly controlled type 2 diabetes mellitus (T2DM) resulting in an increase in bone marrow fat, has led to a focus on whether obesity may also result in alterations in the bone marrow compartment causing a change in bone density. ${ }^{55}$ Adolescence is a time when hematopoietic marrow is progressively converted to fatty marrow. Red marrow is progressively replaced by fatty marrow in the long bones beginning in the epiphyses, followed by the diaphyses, and then the distal and proximal metaphyses. In contrast, red marrow may persist in the axial skeleton into adulthood. ${ }^{56}$ Therefore, an understanding of the relationship between marrow adipose tissue (MAT) and bone microarchitecture may provide insight into some of the changes in trabecular microarchitecture observed in obese children, and an understanding as to why a reduction in BMD in obese children is primarily observed during adolescence. Earlier studies using computed tomography $(\mathrm{CT})$ pointed towards a reciprocal relationship between bone marrow adiposity and the amount of bone in the axial and appendicular skeleton in healthy adolescents and young adults regardless of sex, that was unrelated to BMI or adiposity, supporting the concept that subcutaneous and visceral fat compartments are unrelated to and possess different functional properties compared to bone marrow fat. Instead, the inverse relationship observed between marrow fat and bone may underpin the common mesenchymal origin of adipocytes and osteoblasts. $^{57,58}$ In a more recent study of obese adolescents aged 17-21 years, proton magnetic resonance spectroscopy was used to measure MAT, total, and trabecular volumetric BMD. Trabecular number at the distal tibia measured by HRpQCT was inversely associated with MAT at the distal tibia, but not with lumbar spine MAT. ${ }^{59}$ Conversely, trabecular spacing was positively correlated with distal tibial MAT. A reduction in distal tibial strength proxies was also observed with higher distal tibial MAT, although correlations were not significant. Notably, appendicular and axial MAT were not associated with BMI or DXA measured fat mass (although the BMI range was already high at $35.2-55.5 \mathrm{~kg} / \mathrm{m}^{2}$ ), suggesting that MAT in obese adolescents is regulated differently from subcutaneous and visceral adipose tissue, and that the effects of distal tibial MAT on the surrounding trabecular compartment may result from paracrine and physical interactions with the microenvironment. For example, age-related marrow adipogenesis is linked to an increased expression of RANK-ligand with the downregulation of osteoprotegerin (an osteoclastogenic inhibitor), which in turn may promote osteoclastogenesis and subsequent bone resorption. ${ }^{60}$ Given that osteoblasts and bone marrow adipocytes share a common mesenchymal stromal cell progenitor, the lineage commitment of the progenitor cells towards a specific cell type based upon mutually exclusive transcriptional activators ${ }^{61}$ may play a key role in the fate of skeletal development in the bone microenvironment.

\section{THE INFLUENCE OF VISCERAL AND SUBCUTANEOUS ADIPOSE TISSUE ON BONE MASS IN CHILDREN}

Until recently the majority of childhood studies focused on the overall relationship between excess fat and bone without considering the relative influence of different fat compartments. Adverse metabolic changes in relation to obesity leading to diseases including T2DM, stroke, and cardiovascular disease are associated with an increase in visceral adiposity, a fat compartment that has remained relatively unexplored in pediatric studies of skeletal structure and development. ${ }^{62,63}$ Similarly, regional analysis of fat demonstrates that visceral adipose tissue may confer a more deleterious effect on bone compared to subcutaneous fat in obese children due to the excess production of visceral adipose tissue cytokines, an alteration in serum adipokines ${ }^{19}$, resulting in a reduction in bone mineral accretion ${ }^{38}$ that persists into young adulthood. ${ }^{64}$ This has been observed in the lower limbs at femoral sites suggesting that the weight bearing effects of increasing fat mass are counteracted by the deleterious effects of visceral fat accumulation. ${ }^{38}$ Furthermore, evidence suggests that the accumulation of visceral fat may impair the development of cortical bone during skeletal development ${ }^{19}$, supporting cross-sectional observations demonstrating that the positive relationship between fat and bone attenuates and reverses with increasing adiposity. ${ }^{34}$ More work is required to determine the threshold of central adiposity required to impair skeletal 
development and to further explore the previous observation that ethnic origins may influence the impact of intra-abdominal and subcutaneous fat on bone mass in children. ${ }^{65}$ While evaluating the impact on bone quantity is important, assessing the impact of adipose compartments on bone strength provides better insight as to why obesity during skeletal growth incurs a higher fracture risk. Moreover, sex-related changes in body fat distribution that occur during development are often not accounted for in cross- sectional studies. Recently, a longitudinal study in 11-19-year-olds evaluating the relationships between visceral and subcutaneous adipose tissue in relation to SSI measured by pQCT demonstrated possible sex differences in the fat-bone relationship relating to fat compartments. ${ }^{66}$ In females, visceral fat was inversely related to radial bone strength whereas subcutaneous and total fat mass were negatively related to radial bone strength in males. These sex differences in the relationship between fat deposits and bone strength in children and young people require further exploration.

\section{BROWN ADIPOSE TISSUE AND BONE IN CHILDREN}

While the relationship between white adipose tissue and skeletal development has been extensively studied, the role of brown adipose tissue (BAT) in relation to skeletal development and bone mass has only recently emerged. BAT, derived from the same progenitors as myocytes, is a metabolically active form of fat, with a primary function of thermoregulation by nonshivering thermogenesis. Through the action of uncoupling protein-1, BAT dissipates the electrochemical energy in the mitochondrial respiratory chain as heat. BAT is relatively abundant in newborns and diminishes in adults as they age, but remains in adults as supraclavicular, renal, and spinal deposits. ${ }^{67,68}$ While still relatively limited, evidence is emerging that BAT is positively correlated to bone mass. Women with detectable cold-activated BAT (in the supraclavicular and paravertebral regions), as determined by fluorodeoxyglucose positron emission tomography/CT, have a higher total and vertebral $\mathrm{BMD}$ with a positive correlation between BAT volume and BMD. ${ }^{69,70}$ At a microarchitectural level, BAT appears to be positively correlated with the femoral CSA in children and adults. ${ }^{71,72}$ Further work is needed to define the role of BAT in skeletal metabo- lism and development. Interestingly, despite a long period of inactivity, hibernating mammals maintain muscle and bone mass in an environment of increased brown fat suggesting that brown fat may be fundamental for the maintenance of bone mass. ${ }^{73}$ The finding that brown fat is inversely related to BMI particularly during aging ${ }^{74}$ may point to novel mechanisms underpinning the relationship between obesity and skeletal development.

\section{HORMONAL MECHANISMS UNDERPINNING THE FAT-BONE RELATIONSHIP}

The accumulation of excess adipose tissue in childhood obesity results in an alteration in the hormonal environment that could potentially alter skeletal development. This includes a change in adipokines and inflammatory cytokines. Leptin is a hormone that is produced exclusively by fat and was initially identified as a hormone fundamental in the control of satiety. Leptin is an adipocyteproduced hormone that inhibits appetite and favors energy expenditure primarily through its action on the arcuate nucleus of the hypothalamus. ${ }^{75}$ Given the emerging relationships between fat mass and bone in adults and children on a background of increasing obesity, leptin was identified as a possible candidate hormone linking fat and bone. Early studies demonstrated that leptin directly exerts an osteogenic effect on bone. In both in vitro and in vivo studies, leptin acts directly through osteoblast receptors on human marrow stromal cells to promote osteoblast proliferation and differentiation while inhibiting adipocyte differentiation and osteoclastogenesis through generation of osteoprotegerin. ${ }^{76,77}$ In studies in mice that followed, it was demonstrated that leptin also acts centrally on the ventromedial hypothalamus and through efferent sympathetic pathways exerting an antiosteogenic effect through $\beta 2$ adrenergic receptors in osteoblasts. ${ }^{78,79}$ Later studies revealed that sympathetic signaling in osteoblasts is responsible for a more complex regulatory control of osteoblast function through the inhibition of osteoblast proliferation via circadian clock genes and that the sympathetic nervous system also favors bone resorption by increasing the expression of RANK-ligand..$^{80}$

Children with congenital leptin deficiency are profoundly overweight yet they appear to have normal age and sex-related whole 
body $\mathrm{BMD}$ despite being hypogonadal and having hyperparathyroidism. ${ }^{81,82} \mathrm{~A}$ recent report of two children with mutations in the leptin receptor demonstrated a high bone mass phenotype ${ }^{83}$ supporting animal studies that leptin acts centrally to control bone mass and that leptin deficiency is protective for the developing skeleton. In studies of obese children, leptin is associated with a reduction in bone mass and trabecular thickness and an increase in cortical porosity which may be related to changes in bone signaling and subsequently bone turnover. ${ }^{42,50,84}$ In cohorts of predominantly normal weight children, these associations are not demonstrated. ${ }^{85,86}$ In vivo studies in tail-suspended rats demonstrated that lower doses of leptin appeared to be osteoprotective, but at higher doses, bone loss is increased by bone resorption and reduced bone formation. Cumulatively, this implies that a threshold exists by which leptin may change from exerting a positive to a detrimental effect on bone as fat mass increases. Adiponectin, like leptin, is an adipocyte-derived hormone encoded by the $A D I P O Q$ gene and is well-known for its role in energy metabolism, but is paradoxically lower in obesity. ${ }^{87}$ In children and adults, an inverse relationship exists between adiponectin and bone suggesting that lower adiponectin in obesity may protect the skeleton ${ }^{88,89}$, an observation that contradicts findings in animal studies demonstrating that adiponectin deficiency has a negative impact on both cortical and trabecular compartments. ${ }^{90}$ More recently, animal studies have demonstrated opposing peripheral and central effects of adiponectin on the skeleton during ageing. Early in life adiponectin acts directly on osteoblasts to prevent their proliferation and increase osteoblast apoptosis; as animals mature this action is obscured by adiponectin signaling centrally in the neurons of the locus coeruleus to decrease sympathetic tone increasing bone mass and decreasing energy expenditure. ${ }^{91}$ However, studies in humans have yet to demonstrate a differential action of adiponectin on the developing skeleton or related to ageing.

Childhood is a time of significant hormonal changes that can be altered by obesity. Growth hormone is fundamental for bone mineral accretion in the developing skeleton and promotes osteoblast differentiation, myogenesis, and muscle development. ${ }^{92,93}$ As high levels of visceral adiposity in both children and adults impairs growth hormone secretion and the response of growth hormone secretion to stimuli ${ }^{94,95}$, this may have a negative impact on bone mass accrual. The obesity-related rise in insulin may have a direct effect on pituitary inhibiting growth hormone secretion. ${ }^{96}$ Growth hormone is also fundamental in promoting the hepatic release of insulin-like growth factor 1 which in-turn promotes growth plate chondrogenesis ${ }^{97}$ and osteoblastogenesis. ${ }^{98}$ Insulin resistance results from the long-term accumulation of excess fat. Therefore, in early years, obesity-related excess secretion of insulin may result in an overall net gain in bone, given that osteoblasts express insulin receptors ${ }^{99}$ and insulin is anabolic promoting osteoblast proliferation, collagen synthesis, and alkaline phosphatase production..$^{100}$ However, over time, the development of insulin resistance results in lower bone mass in obese children ${ }^{42}$ and an increased fracture risk in patients with T2DM. ${ }^{101,102}$ This proposed change in the relationship between insulin, insulin resistance, and bone development over time may provide a mechanistic explanation as to the changing relationship between fat mass and bone mass seen across childhood and adolescence.

Many of the hormonal changes seen during adolescence appear to confer a positive effect on skeletal development which is understandable given that around $25 \%$ of bone mass is achieved, and peak bone mass accrual occurs during this period. ${ }^{3}$ Testosterone and estrogen rise in both females and males during the pubertal period and adrenal androgen levels are higher in prepubertal obese children compared to healthy weight children, but this only appears to persist in obese pubertal females. ${ }^{103}$ Similarly, the adrenal secretion of 11-deoxycortisol, cortisol, and cortisone collectively known as glucocorticoids is also elevated in prepubertal obese children. ${ }^{104} \mathrm{An}$ drogens stimulate the differentiation and proliferation of osteoblasts through androgen receptors, decrease osteoblast and osteocyte apoptosis, and indirectly and directly modify osteoclastogenesis in favor of a reduction in bone resorption. ${ }^{105-107}$ In mice completely lacking androgen receptors, a reduction in trabecular and cortical bone mass has been observed. ${ }^{108}$ Conversely, the excessive production of glucocorticoids results in the inhibition of osteoblastogenesis, reduced bone formation through the canonical Wnt-signaling pathway ${ }^{109}$, increased osteoblast apoptosis, and a reduction in osteoclast differentiation through the upregulation of the RANK-ligand pathway. ${ }^{110}$ Fat deposits contain aromatase, and thus childhood obesity may result in the increased aromatization of testosterone and other androgens to estrogens which may augment bone 
mass in a protective manner similar to that observed in obese postmenopausal women. ${ }^{107}$ Therefore, it is surprising that despite a hormonal environment in obese adolescents that should confer a relatively favorable environment for skeletal development and adaptation, bone mass accrual does not appear to respond appropriately to an increase in mechanical loading or hormonal stimuli which in turn leads to an increased propensity to fracture. In summary, obesity results in a significant number of hormonal changes during growth and development either directly through the release of adipokines, or indirectly through an alternation in sex steroids, metabolic hormones, and androgens. One of the challenges ahead is to determine the hierarchical role of each of these hormones on influencing bone accretion during development in an obesogenic environment.

\section{CONCLUSION}

The recent decades have seen a considerable increase in our understanding of the relationship between fat and bone, and the im- pact of childhood obesity on the developing skeleton. A multitude of factors contribute to the complex interaction and relationship between fat and bone in children summarized in Fig. 3 that merit further research. Other factors may be identified in the future that will add to the growing list of environmental and physiological changes that affect the growing skeleton in relation to childhood obesity. Despite progress in this field, further clarity is required to determine whether the deleterious effect of fat is site- and sex-specific, related to changes that also occur within the bone marrow microenvironment, and confined to a specific age range or associated with visceral fat and a metabolically unfavorable environment. A wide variation exists among children in stature, body composition, rate of growth, and timing of biological maturation. Since obese compared to healthy weight children of the same age are generally further advanced in physiological and skeletal maturity, comparing the effects on obesity on bone at any given age presents challenges. Moreover, the relationship between obesity and bone is likely to change during childhood and adolescence. It is likely that a critical

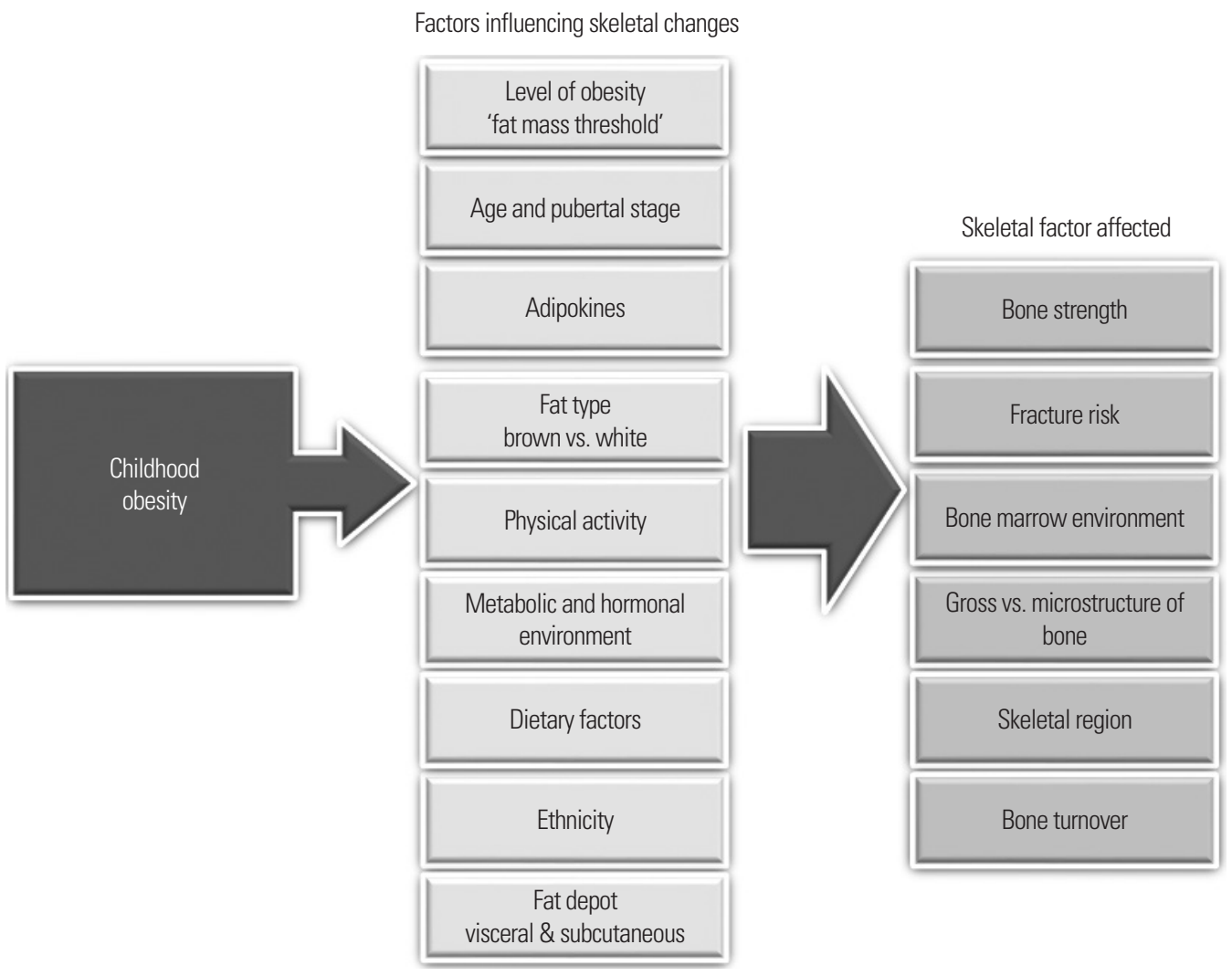

Figure 3. A summary of the environmental and physiological factors impacting the relationship between childhood obesity and bone, providing a platform for further work in these areas. The diagram summarizes the factors influencing skeletal changes and skeletal factors that may change as a result of childhood obesity. 
threshold of excess fat mass needs to be reached to reverse the potentially positive effects of fat on bone which in part may be related to a change in the hormonal milieu that may be dependent on the stage of physiological maturity. The advent of new skeletal imaging modalities has led to a shift in focus from assessing the quantity of bone to evaluating the biomechanical determinants of bone underpinning bone strength and fracture risk. Given that obese children are over-represented in fracture groups and peak bone mass is a determinant of future skeletal health and osteoporosis, further studies are required to understand how childhood obesity affects skeletal maturation and development.

\section{CONFLICTS OF INTEREST}

The author declares no conflict of interest.

\section{REFERENCES}

1. Theintz G, Buchs B, Rizzoli R, Slosman D, Clavien H, Sizonenko PC, et al. Longitudinal monitoring of bone mass accumulation in healthy adolescents: evidence for a marked reduction after 16 years of age at the levels of lumbar spine and femoral neck in female subjects. J Clin Endocrinol Metab 1992;75:1060-5.

2. Guéguen R, Jouanny P, Guillemin F, Kuntz C, Pourel J, Siest G. Segregation analysis and variance components analysis of bone mineral density in healthy families. J Bone Miner Res 1995; 10:2017-22.

3. Heaney RP, Abrams S, Dawson-Hughes B, Looker A, Marcus R, Matkovic V, et al. Peak bone mass. Osteoporos Int 2000;11:985-1009.

4. Bachrach LK. Osteoporosis and measurement of bone mass in children and adolescents. Endocrinol Metab Clin North Am 2005;34:521-35.

5. Manias K, McCabe D, Bishop N. Fractures and recurrent fractures in children; varying effects of environmental factors as well as bone size and mass. Bone 2006;39:652-7.

6. Goulding A, Grant AM, Williams SM. Bone and body composition of children and adolescents with repeated forearm fractures. J Bone Miner Res 2005;20:2090-6.
7. Goulding A, Cannan R, Williams SM, Gold EJ, Taylor RW, Lewis-Barned NJ. Bone mineral density in girls with forearm fractures. J Bone Miner Res 1998;13:143-8.

8. Goulding A, Taylor RW, Jones IE, McAuley KA, Manning PJ, Williams SM. Overweight and obese children have low bone mass and area for their weight. Int J Obes Relat Metab Disord 2000;24:627-32.

9. Fornari ED, Suszter M, Roocroft J, Bastrom T, Edmonds EW, Schlechter J. Childhood obesity as a risk factor for lateral condyle fractures over supracondylar humerus fractures. Clin Orthop Relat Res 2013;471:1193-8.

10. Khosla S, Melton LJ 3rd, Dekutoski MB, Achenbach SJ, Oberg AL, Riggs BL. Incidence of childhood distal forearm fractures over 30 years: a population-based study. JAMA 2003;290:1479-85.

11. Skaggs DL, Loro ML, Pitukcheewanont P, Tolo V, Gilsanz V. Increased body weight and decreased radial cross-sectional dimensions in girls with forearm fractures. J Bone Miner Res 2001;16:1337-42.

12. Kirmani S, Christen D, van Lenthe GH, Fischer PR, Bouxsein ML, McCready LK, et al. Bone structure at the distal radius during adolescent growth. J Bone Miner Res 2009;24: 1033-42.

13. Nishiyama KK, Macdonald HM, Moore SA, Fung T, Boyd SK, McKay HA. Cortical porosity is higher in boys compared with girls at the distal radius and distal tibia during pubertal growth: an HR-pQCT study. J Bone Miner Res 2012;27: 273-82.

14. Goulding A, Jones IE, Taylor RW, Manning PJ, Williams SM. More broken bones: a 4-year double cohort study of young girls with and without distal forearm fractures. J Bone Miner Res 2000;15:2011-8.

15. Wearing SC, Hennig EM, Byrne NM, Steele JR, Hills AP. The impact of childhood obesity on musculoskeletal form. Obes Rev 2006;7:209-18.

16. Colné $P$, Frelut ML, Pérès G, Thoumie P. Postural control in obese adolescents assessed by limits of stability and gait initiation. Gait Posture 2008;28:164-9.

17. Deforche BI, Hills AP, Worringham CJ, Davies PS, Murphy AJ, Bouckaert JJ, et al. Balance and postural skills in normal- 
weight and overweight prepubertal boys. Int J Pediatr Obes 2009;4:175-82.

18. Júnior IF, Cardoso JR, Christofaro DG, Codogno JS, de Moraes AC, Fernandes RA. The relationship between visceral fat thickness and bone mineral density in sedentary obese children and adolescents. BMC Pediatr 2013;13:37.

19. Russell M, Mendes N, Miller KK, Rosen CJ, Lee H, Klibanski A, et al. Visceral fat is a negative predictor of bone density measures in obese adolescent girls. J Clin Endocrinol Metab 2010;95:1247-55.

20. Clark EM, Tobias JH, Ness AR. Association between bone density and fractures in children: a systematic review and meta-analysis. Pediatrics 2006;117:e291-7.

21. Bishop N, Arundel P, Clark E, Dimitri P, Farr J, Jones G, et al. Fracture prediction and the definition of osteoporosis in children and adolescents: the ISCD 2013 Pediatric Official Positions. J Clin Densitom 2014;17:275-80.

22. Kim SJ, Ahn J, Kim HK, Kim JH. Obese children experience more extremity fractures than nonobese children and are significantly more likely to die from traumatic injuries. Acta Paediatr 2016;105:1152-7.

23. Kessler J, Koebnick C, Smith N, Adams A. Childhood obesity is associated with increased risk of most lower extremity fractures. Clin Orthop Relat Res 2013;471:1199-207.

24. Fewtrell MS; British Paediatric \& Adolescent Bone Group. Bone densitometry in children assessed by dual $\mathrm{x}$ ray absorptiometry: uses and pitfalls. Arch Dis Child 2003;88:795-8.

25. van Leeuwen J, Koes BW, Paulis WD, van Middelkoop M. Differences in bone mineral density between normal-weight children and children with overweight and obesity: a systematic review and meta-analysis. Obes Rev 2017;18:526-46.

26. Dimitri P, Bishop N, Walsh JS, Eastell R. Obesity is a risk factor for fracture in children but is protective against fracture in adults: a paradox. Bone 2012;50:457-66.

27. Leonard MB, Shults J, Wilson BA, Tershakovec AM, Zemel BS. Obesity during childhood and adolescence augments bone mass and bone dimensions. Am J Clin Nutr 2004;80: 514-23.

28. Hernandez CJ, Beaupré GS, Carter DR. A theoretical analysis of the relative influences of peak BMD, age-related bone loss and menopause on the development of osteoporosis. Osteoporos Int 2003;14:843-7.

29. Wren TA, Kalkwarf HJ, Zemel BS, Lappe JM, Oberfield S, Shepherd JA, et al. Longitudinal tracking of dual-energy Xray absorptiometry bone measures over 6 years in children and adolescents: persistence of low bone mass to maturity. J Pediatr 2014;164:1280-5.

30. Foley S, Quinn S, Jones G. Tracking of bone mass from childhood to adolescence and factors that predict deviation from tracking. Bone 2009;44:752-7.

31. Sudhagoni RG, Wey HE, Djira GD, Specker BL. Longitudinal effects of fat and lean mass on bone accrual in infants. Bone 2012;50:638-42.

32. Clark EM, Ness AR, Tobias JH. Adipose tissue stimulates bone growth in prepubertal children. J Clin Endocrinol Metab 2006;91:2534-41.

33. Sayers A, Marcus M, Rubin C, McGeehin MA, Tobias JH. Investigation of sex differences in hip structure in peripubertal children. J Clin Endocrinol Metab 2010;95:3876-83.

34. Wey HE, Binkley TL, Beare TM, Wey CL, Specker BL. Crosssectional versus longitudinal associations of lean and fat mass with pQCT bone outcomes in children. J Clin Endocrinol Metab 2011;96:106-14.

35. Jones IE, Taylor RW, Williams SM, Manning PJ, Goulding A. Four-year gain in bone mineral in girls with and without past forearm fractures: a DXA study. Dual energy X-ray absorptiometry. J Bone Miner Res 2002;17:1065-72.

36. Burrows M, Baxter-Jones A, Mirwald R, Macdonald H, McKay $\mathrm{H}$. Bone mineral accrual across growth in a mixed-ethnic group of children: are Asian children disadvantaged from an early age? Calcif Tissue Int 2009;84:366-78.

37. Wosje KS, Khoury PR, Claytor RP, Copeland KA, Kalkwarf HJ, Daniels SR. Adiposity and TV viewing are related to less bone accrual in young children. J Pediatr 2009;154:79-85.

38. Laddu DR, Farr JN, Laudermilk MJ, Lee VR, Blew RM, Stump C, et al. Longitudinal relationships between whole body and central adiposity on weight-bearing bone geometry, density, and bone strength: a pQCT study in young girls. Arch Osteoporos 2013;8:156.

39. Kindler JM, Lobene AJ, Vogel KA, Martin BR, McCabe LD, 
Peacock M, et al. Adiposity, insulin resistance, and bone mass in children and adolescents. J Clin Endocrinol Metab 2019; 104:892-9.

40. Pollock NK, Bernard PJ, Wenger K, Misra S, Gower BA, Allison JD, et al. Lower bone mass in prepubertal overweight children with prediabetes. J Bone Miner Res 2010;25:2760-9.

41. Kindler JM, Pollock NK, Laing EM, Oshri A, Jenkins NT, Isales CM, et al. Insulin resistance and the IGF-I-cortical bone relationship in children ages 9 to 13 years. J Bone Miner Res 2017;32:1537-45.

42. Pollock NK, Bernard PJ, Gutin B, Davis CL, Zhu H, Dong Y. Adolescent obesity, bone mass, and cardiometabolic risk factors. J Pediatr 2011;158:727-34.

43. Afghani A, Cruz ML, Goran MI. Impaired glucose tolerance and bone mineral content in overweight Latino children with a family history of type 2 diabetes. Diabetes Care 2005;28: 372-8.

44. Cheung AM, Adachi JD, Hanley DA, Kendler DL, Davison KS, Josse R, et al. High-resolution peripheral quantitative computed tomography for the assessment of bone strength and structure: a review by the Canadian Bone Strength Working Group. Curr Osteoporos Rep 2013;11:136-46.

45. Farr JN, Amin S, Melton LJ 3rd, Kirmani S, McCready LK, Atkinson EJ, et al. Bone strength and structural deficits in children and adolescents with a distal forearm fracture resulting from mild trauma. J Bone Miner Res 2014;29:590-9.

46. Kontulainen SA, Johnston JD, Liu D, Leung C, Oxland TR, McKay HA. Strength indices from pQCT imaging predict up to $85 \%$ of variance in bone failure properties at tibial epiphysis and diaphysis. J Musculoskelet Neuronal Interact 2008; 8:401-9.

47. Stagi S, Cavalli L, Cavalli T, de Martino M, Brandi ML. Peripheral quantitative computed tomography (pQCT) for the assessment of bone strength in most of bone affecting conditions in developmental age: a review. Ital J Pediatr 2016; 42:88.

48. Wetzsteon RJ, Petit MA, Macdonald HM, Hughes JM, Beck TJ, McKay HA. Bone structure and volumetric BMD in overweight children: a longitudinal study. J Bone Miner Res 2008;23:1946-53.
49. Ducher G, Bass SL, Naughton GA, Eser P, Telford RD, Daly RM. Overweight children have a greater proportion of fat mass relative to muscle mass in the upper limbs than in the lower limbs: implications for bone strength at the distal forearm. Am J Clin Nutr 2009;90:1104-11.

50. Janicka A, Wren TA, Sanchez MM, Dorey F, Kim PS, Mittelman SD, et al. Fat mass is not beneficial to bone in adolescents and young adults. J Clin Endocrinol Metab 2007; 92:143-7.

51. Dimitri P, Jacques RM, Paggiosi M, King D, Walsh J, Taylor ZA, et al. Leptin may play a role in bone microstructural alterations in obese children. J Clin Endocrinol Metab 2015; 100:594-602.

52. Farr JN, Amin S, LeBrasseur NK, Atkinson EJ, Achenbach SJ, McCready LK, et al. Body composition during childhood and adolescence: relations to bone strength and microstructure. J Clin Endocrinol Metab 2014;99:4641-8.

53. Chan GK, Duque G. Age-related bone loss: old bone, new facts. Gerontology 2002;48:62-71.

54. Wehrli FW, Hopkins JA, Hwang SN, Song HK, Snyder PJ, Haddad JG. Cross-sectional study of osteopenia with quantitative MR imaging and bone densitometry. Radiology 2000;217:527-38.

55. Veldhuis-Vlug AG, Rosen CJ. Mechanisms of marrow adiposity and its implications for skeletal health. Metabolism 2017;67:106-14.

56. Kricun ME. Red-yellow marrow conversion: its effect on the location of some solitary bone lesions. Skeletal Radiol 1985; 14:10-9.

57. Di Iorgi N, Rosol M, Mittelman SD, Gilsanz V. Reciprocal relation between marrow adiposity and the amount of bone in the axial and appendicular skeleton of young adults. J Clin Endocrinol Metab 2008;93:2281-6.

58. Di Iorgi N, Mo AO, Grimm K, Wren TA, Dorey F, Gilsanz V. Bone acquisition in healthy young females is reciprocally related to marrow adiposity. J Clin Endocrinol Metab 2010; 95:2977-82.

59. Singhal V, Torre Flores LP, Stanford FC, Toth AT, Carmine B, Misra M, et al. Differential associations between appendicular and axial marrow adipose tissue with bone microarchi- 
tecture in adolescents and young adults with obesity. Bone 2018;116:203-6.

60. Takeshita S, Fumoto T, Naoe Y, Ikeda K. Age-related marrow adipogenesis is linked to increased expression of RANKL. J Biol Chem 2014;289:16699-710.

61. Nakashima K, de Crombrugghe B. Transcriptional mechanisms in osteoblast differentiation and bone formation. Trends Genet 2003;19:458-66.

62. Koster A, Stenholm S, Alley DE, Kim LJ, Simonsick EM, Kanaya AM, et al. Body fat distribution and inflammation among obese older adults with and without metabolic syndrome. Obesity (Silver Spring) 2010;18:2354-61.

63. Shah RV, Murthy VL, Abbasi SA, Blankstein R, Kwong RY, Goldfine $A B$, et al. Visceral adiposity and the risk of metabolic syndrome across body mass index: the MESA Study. JACC Cardiovasc Imaging 2014;7:1221-35.

64. Gilsanz V, Chalfant J, Mo AO, Lee DC, Dorey FJ, Mittelman $\mathrm{SD}$. Reciprocal relations of subcutaneous and visceral fat to bone structure and strength. J Clin Endocrinol Metab 2009; 94:3387-93.

65. Afghani A, Goran MI. Racial differences in the association of subcutaneous and visceral fat on bone mineral content in prepubertal children. Calcif Tissue Int 2006;79:383-8.

66. Glass NA, Torner JC, Letuchy EM, Burns TL, Janz KF, Eichenberger Gilmore JM, et al. Does visceral or subcutaneous fat influence peripheral cortical bone strength during adolescence? a longitudinal study. J Bone Miner Res 2018; 33:580-8.

67. Cannon B, Nedergaard J. Brown adipose tissue: function and physiological significance. Physiol Rev 2004;84:277-359.

68. Enerbäck S. Human brown adipose tissue. Cell Metab 2010; 11:248-52.

69. Bredella MA, Fazeli PK, Freedman LM, Calder G, Lee H, Rosen CJ, et al. Young women with cold-activated brown adipose tissue have higher bone mineral density and lower Pref-1 than women without brown adipose tissue: a study in women with anorexia nervosa, women recovered from anorexia nervosa, and normal-weight women. J Clin Endocrinol Metab 2012;97:E584-90.

70. Lee P, Brychta RJ, Collins MT, Linderman J, Smith S, Her- scovitch P, et al. Cold-activated brown adipose tissue is an independent predictor of higher bone mineral density in women. Osteoporos Int 2013;24:1513-8.

71. Bredella MA, Gill CM, Rosen CJ, Klibanski A, Torriani M. Positive effects of brown adipose tissue on femoral bone structure. Bone 2014;58:55-8.

72. Ponrartana S, Aggabao PC, Hu HH, Aldrovandi GM, Wren TA, Gilsanz V. Brown adipose tissue and its relationship to bone structure in pediatric patients. J Clin Endocrinol Metab 2012;97:2693-8.

73. Egginton S, Fairney J, Bratcher J. Differential effects of cold exposure on muscle fibre composition and capillary supply in hibernator and non-hibernator rodents. Exp Physiol 2001; 86:629-39.

74. Cypess AM, Lehman S, Williams G, Tal I, Rodman D, Goldfine $\mathrm{AB}$, et al. Identification and importance of brown adipose tissue in adult humans. N Engl J Med 2009;360:1509-17.

75. Halaas JL, Gajiwala KS, Maffei M, Cohen SL, Chait BT, Rabinowitz D, et al. Weight-reducing effects of the plasma protein encoded by the obese gene. Science 1995;269:543-6.

76. Thomas T, Gori F, Khosla S, Jensen MD, Burguera B, Riggs BL. Leptin acts on human marrow stromal cells to enhance differentiation to osteoblasts and to inhibit differentiation to adipocytes. Endocrinology 1999;140:1630-8.

77. Holloway WR, Collier FM, Aitken CJ, Myers DE, Hodge JM, Malakellis M, et al. Leptin inhibits osteoclast generation. J Bone Miner Res 2002;17:200-9.

78. Takeda S, Elefteriou F, Levasseur R, Liu X, Zhao L, Parker $\mathrm{KL}$, et al. Leptin regulates bone formation via the sympathetic nervous system. Cell 2002;111:305-17.

79. Elefteriou F, Ahn JD, Takeda S, Starbuck M, Yang X, Liu X, et al. Leptin regulation of bone resorption by the sympathetic nervous system and CART. Nature 2005;434:514-20.

80. Kondo H, Togari A. Continuous treatment with a low-dose $\beta$-agonist reduces bone mass by increasing bone resorption without suppressing bone formation. Calcif Tissue Int 2011; 88:23-32.

81. Montague CT, Farooqi IS, Whitehead JP, Soos MA, Rau H, Wareham NJ, et al. Congenital leptin deficiency is associated with severe early-onset obesity in humans. Nature 1997;387: 
903-8.

82. Farooqi IS, Jebb SA, Langmack G, Lawrence E, Cheetham $\mathrm{CH}$, Prentice AM, et al. Effects of recombinant leptin therapy in a child with congenital leptin deficiency. N Engl J Med 1999;341:879-84.

83. Hannema SE, Wit JM, Houdijk ME, van Haeringen A, Bik EC, Verkerk AJ, et al. Novel leptin receptor mutations identified in two girls with severe obesity are associated with increased bone mineral density. Horm Res Paediatr 2016;85: 412-20.

84. Dimitri P, Wales JK, Bishop N. Adipokines, bone-derived factors and bone turnover in obese children; evidence for altered fat-bone signalling resulting in reduced bone mass. Bone 2011;48:189-96.

85. Roemmich JN, Clark PA, Mantzoros CS, Gurgol CM, Weltman A, Rogol AD. Relationship of leptin to bone mineralization in children and adolescents. J Clin Endocrinol Metab 2003;88:599-604.

86. Garnett SP, Högler W, Blades B, Baur LA, Peat J, Lee J, et al. Relation between hormones and body composition, including bone, in prepubertal children. Am J Clin Nutr 2004;80: 966-72.

87. Stefan N, Stumvoll M. Adiponectin: its role in metabolism and beyond. Horm Metab Res 2002;34:469-74.

88. Lenchik L, Register TC, Hsu FC, Lohman K, Nicklas BJ, Freedman BI, et al. Adiponectin as a novel determinant of bone mineral density and visceral fat. Bone 2003;33:646-51.

89. Richards JB, Valdes AM, Burling K, Perks UC, Spector TD. Serum adiponectin and bone mineral density in women. $\mathrm{J}$ Clin Endocrinol Metab 2007;92:1517-23.

90. Naot D, Watson M, Callon KE, Tuari D, Musson DS, Choi AJ, et al. Reduced bone density and cortical bone indices in female adiponectin-knockout mice. Endocrinology 2016; 157:3550-61.

91. Kajimura D, Lee HW, Riley KJ, Arteaga-Solis E, Ferron M, Zhou B, et al. Adiponectin regulates bone mass via opposite central and peripheral mechanisms through FoxO1. Cell Metab 2013;17:901-15.

92. Gevers EF, Loveridge N, Robinson IC. Bone marrow adipocytes: a neglected target tissue for growth hormone. Endo- crinology 2002;143:4065-73.

93. Florini JR, Ewton DZ, Coolican SA. Growth hormone and the insulin-like growth factor system in myogenesis. Endocr Rev 1996;17:481-517.

94. Williams T, Berelowitz M, Joffe SN, Thorner MO, Rivier J, Vale W, et al. Impaired growth hormone responses to growth hormone-releasing factor in obesity: a pituitary defect reversed with weight reduction. N Engl J Med 1984;311:1403-7.

95. Bonert VS, Elashoff JD, Barnett P, Melmed S. Body mass index determines evoked growth hormone $(\mathrm{GH})$ responsiveness in normal healthy male subjects: diagnostic caveat for adult GH deficiency. J Clin Endocrinol Metab 2004;89: 3397-401.

96. Luque RM, Kineman RD. Impact of obesity on the growth hormone axis: evidence for a direct inhibitory effect of hyperinsulinemia on pituitary function. Endocrinology 2006; 147:2754-63.

97. Longobardi L, O’Rear L, Aakula S, Johnstone B, Shimer K, Chytil A, et al. Effect of IGF-I in the chondrogenesis of bone marrow mesenchymal stem cells in the presence or absence of TGF-beta signaling. J Bone Miner Res 2006;21:626-36.

98. Zhang W, Shen X, Wan C, Zhao Q, Zhang L, Zhou Q, et al. Effects of insulin and insulin-like growth factor 1 on osteoblast proliferation and differentiation: differential signalling via Akt and ERK. Cell Biochem Funct 2012;30:297-302.

99. Levy JR, Murray E, Manolagas S, Olefsky JM. Demonstration of insulin receptors and modulation of alkaline phosphatase activity by insulin in rat osteoblastic cells. Endocrinology 1986;119:1786-92.

100. Thrailkill KM, Liu L, Wahl EC, Bunn RC, Perrien DS, Cockrell GE, et al. Bone formation is impaired in a model of type 1 diabetes. Diabetes 2005;54:2875-81.

101. Leslie WD, Rubin MR, Schwartz AV, Kanis JA. Type 2 diabetes and bone. J Bone Miner Res 2012;27:2231-7.

102. Sanches CP, Vianna AG, Barreto FC. The impact of type 2 diabetes on bone metabolism. Diabetol Metab Syndr 2017; 9:85.

103. Reinehr T, de Sousa G, Roth CL, Andler W. Androgens before and after weight loss in obese children. J Clin Endocrinol Metab 2005;90:5588-95. 
104. Reinehr T, Kulle A, Wolters B, Lass N, Welzel M, Riepe F, et al. Steroid hormone profiles in prepubertal obese children before and after weight loss. J Clin Endocrinol Metab 2013;98:E1022-30.

105. Abu EO, Horner A, Kusec V, Triffitt JT, Compston JE. The localization of androgen receptors in human bone. J Clin Endocrinol Metab 1997;82:3493-7.

106. Kasperk CH, Wakley GK, Hierl T, Ziegler R. Gonadal and adrenal androgens are potent regulators of human bone cell metabolism in vitro. J Bone Miner Res 1997;12:464-71.

107. Clarke BL, Khosla S. Androgens and bone. Steroids 2009;
74:296-305.

108. Notini AJ, McManus JF, Moore A, Bouxsein M, Jimenez M, Chiu WS, et al. Osteoblast deletion of exon 3 of the androgen receptor gene results in trabecular bone loss in adult male mice. J Bone Miner Res 2007;22:347-56.

109. Ohnaka K, Tanabe M, Kawate H, Nawata H, Takayanagi R. Glucocorticoid suppresses the canonical Wnt signal in cultured human osteoblasts. Biochem Biophys Res Commun 2005;329:177-81.

110. Canalis E, Delany AM. Mechanisms of glucocorticoid action in bone. Ann N Y Acad Sci 2002;966:73-81. 